Faculty of Education

Journal of Education

$* * *$

\title{
Using Praat to Develop English Majors' EFL Intonation Production
}

\author{
BY \\ Dr. Marwa Said Mustafa El-Garawany \\ Lecturer of Linguistics, Department of English Language and \\ Literature, Faculty of Archaeology and Languages, Matrouh \\ University, Egypt
}

sceipt date: 5 September $2021 \quad$ - Date of acceptance: 25 September2021

\section{DOI: 10.12816/EDUSOHAG.2021.}




\begin{abstract}
:
This study investigated the effect of using Praat on developing the EFL intonation production of English majors whose inefficiency in such a skill constituted the rational for the present study. Participants $(N=40)$ were thirdyear students in the English Department, Faculty of Education, University of Sadat City, during the first semester of the 2020-2021 academic year. They were divided into two groups: an experimental group $(n=20)$ and a control one $(n=20)$. An EFL intonation production test was developed and administered before and after experimentation, which lasted for 4 weeks. During this time, the experimental group students were taught using the speech analysis software Praat while the control group students received regular instruction. The results revealed that the experimental group students achieved significant improvement in EFL intonation production. Thus, using Praat had a positive effect on developing English majors' EFL intonation production.
\end{abstract}

Keywords: Praat- English majors- EFL intonation production. 


\title{
استفدام برناهج Praat لتنهية ههارة التنغيم باللغة الإنبايزية كلغة أجنبية لدي طلاب قسم اللغة الإنجايزية
}

\author{
د الم مروه سعيد مصطفى الجرواني \\ مدرس اللغويات، قسم اللغة الإنجليزية وآدابها، كلية الآثار واللغات \\ جامعة مطروح، مصر الانجئه
}

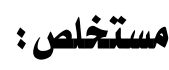

هدفت الدراسة الحالية إلى اختبار أثر استخدام برنامج Praat على تنمية مهارة التنغيم باللغة الإنجليزية كلغة أجنبية لاى طلاب قسم اللغة الإنجليزية. وتكونت عينة الدارسة من ·ـ طالبا من طلاب الفرقة الثالثة بقسم اللغة الإنجليزية بكلية التربية، جامعة مدينة

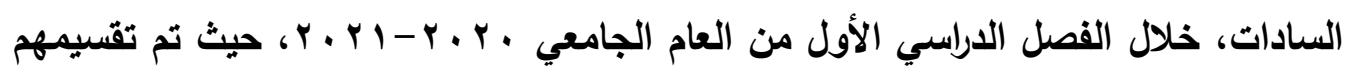

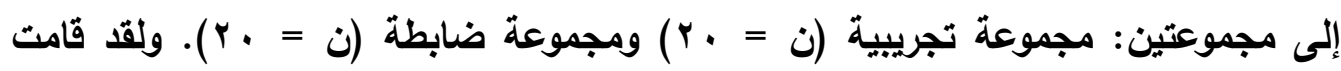

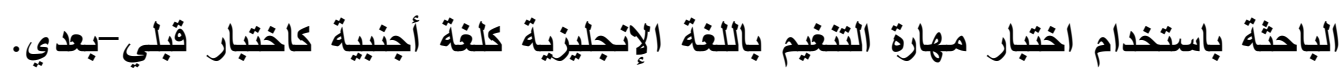
ولقد استغرق التتخل التجريبي أريعة أسابيع، حيث تم التدريس للمجموعة التجريبية باستخدام برنامج التحليل الصوتي Praat أما المجموعة الضابطة فتم التدريس لها بالطريقة المعتادة. ولقد أوضحت نتائج الدراسة أن طلاب المجموعة التجريبية أظهروا تقاماً ذا دلالة إحصائية

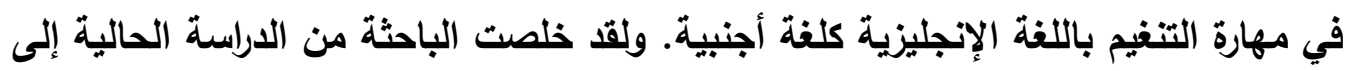
أن استخدام برنامج Praat له أثر دال إحصائياً على تنمية مهارة التنغيم باللغة الإنجليزية كلغة أجنبية لاى طلاب قسم اللغة الإنجليزية. الكلمات المفتاحية: برنامج Praat، مهارة التنغيم باللغة الإنجليزية كلغة أجنبية، طلاب

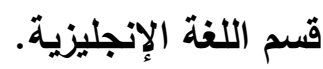




\section{Introduction:}

Phonological research has documented that English intonation is considered "a multilayered and multidimensional system situated at the interface of information structure, morphosyntactic structure, phonological phenomena, and pragmatic functions". Such structural and functional complexity of the intonation system, however, is largely undervalued or even forgotten in second/foreign language (SL/FL) pronunciation pedagogy (Liu \& Reed, 2021, p. 1) which put more emphasis on the accurate production of isolated sounds or words, resulting in a lack of sufficient opportunities to practice intonation and a lack of spontaneous use of its patterns despite successful imitation in language classrooms. Thus, empirical studies on developing SL/FL intonation production are urgently needed (Hsieh, Dong, \& Wang, 2013; Liu \& Reed, 2021).

As computing technology advances, the methods of language learning and teaching vary accordingly: from online language games, practice exercises, and course materials, to chat room exchanges and blogging. The learning and teaching of pronunciation, particularly intonation, should definitely incorporate such advanced technologies in the EFL classroom. Quality digital resources can be easily found on the internet: (a) authentic English speech such as newscasts, movies, and documentaries, (b) online dictionaries with audio pronunciation demonstration, (c) web-based pronunciation practice exercises, (d) online video communication facilities such as Skype, and (e) downloadable speech analysis programs. The capabilities of the last type are fast growing as part of the so-called computer-assisted pronunciation training (CAPT). Speech analysis programs in the past were used exclusively by phoneticians for research purposes (e.g., performing spectrum analysis, labeling speech signals, and generating text reports) because such systems were very complicated to operate. However, many speech analysis programs are much more user-friendly nowadays and they are available as freeware. These programs enable users to record speech and demonstrate their speech signals as visual display. Students and teachers may make use of the visual display to effectively practice different intonation patterns (Li, 2019; Wong, 2016). 
One of the most widely used speech analysis programs is Praat which provides an acoustic analysis of the speech signal, usually in the form of a visualization of the speech waveform, spectrogram, and pitch contour (Hincks, 2015; Pennington \& Rogerson-Revell, 2019) to provide feedback for students to improve their EFL pronunciation and raise awareness of speech errors (Tsai, 2019). It allows students to analyze the visual patterns of their own speech to distinguish how it differs from the target pronunciation. It also enables teachers to analyze their students' intonation patterns for diagnostic and evaluation purposes (Le \& Brook, 2011). Moreover, it promotes students' autonomous learning, since students use it in a self-directed setting where they can control the timing and pace at which they learn. Consequently, it lightens the teaching load of language teachers and enables them to be facilitators rather than the main resources for speech production improvement, particularly with large classes (Le \& Brook, 2011; Tsai, 2019). Thus, using Praat could prove highly useful to enhance EFL English majors' intonation production.

\section{1 Context of the Problem:}

Phonetics and conversation courses constitute a fundamental component in most English undergraduate programs in Egyptian Faculties of Arts, Languages, and Education. English majors at the Faculty of Education, University of Sadat City, are required to study a phonetics course once a year for four years and a conversation course at the same time. It has been noticed that they lack the skills needed to successfully produce intonation in English. Their performance in such dimensions like prominence and tone choice is weak. They often put the primary stress on the wrong syllables or tend to include more prominent syllables than needed in a tone unit which may affect comprehension. Moreover, they misuse the different pitch patterns when speaking, leading to miscomprehension or misrepresentation of the spoken message.

This inefficiency in EFL intonation production of Egyptian English majors may be due to (a) inadequacy in speaking competence and pronunciation knowledge, (b) lack of effective practice and direct inclusion of intonation in their university phonetics and conversation curricula, (c) lack of knowledge in pronunciation pedagogy by their 
teachers, and (d) adhering to the traditional methods and materials in teaching pronunciation (Abd El-Fattah, 2018; Albaaly, 2017a, 2017b; Mohamed, 2010; Salem, 2020). To document the problem, a pilot study was conducted which consisted of an EFL intonation production test administered to 25 third-year English majors from the Faculty of Education, University of Sadat City, during the second semester of the 2019-2020 academic year. The results revealed students' lack of the required EFL intonation production skills.

\section{2 Statement of the Problem:}

The problem of the present study was identified in third-year English majors' obvious weakness in EFL intonation production. Thus, the present study was designed to help such students to improve their EFL intonation production through using Praat.

\section{3 Questions:}

The present study addressed the following questions:

1. To what extent do third-year English majors master EFL intonation production?

2. How can Praat be used to develop third-year English majors' EFL intonation production?

3. What is the effect of using Praat on developing third-year English majors' EFL intonation production?

\section{4 Hypothesis of the Study:}

There would be a statistically significant difference between the mean score of the control group and that of the experimental group in EFL intonation production on the post-administration of the EFL intonation production test in favor of the experimental group.

\section{5 Significance:}

The present study is significant for:

1. Students: as it helps in developing their EFL intonation production.

2. Teachers: as it helps in providing them with the speech analysis software Praat that might help in developing their students' EFL intonation production. 
3. Curriculum planners: as it draws their attention to the efficacy of using Praat in EFL intonation production and integrating it in the EFL phonetics and conversation courses.

\section{6 Terminology:}

In the present study, EFL intonation production is operationally defined as third-year English majors' ability to produce different pitch variations properly in their speech. It is measured in terms of prominence and tone choice. Praat is operationally defined as a speech analysis software by which those students can develop their EFL intonation production.

\section{7 Delimitations:}

The present study was delimited to:

1. Forty third-year students in the English Department, Faculty of Education, University of Sadat City.

2. The first semester of the 2020-2021 academic year.

\section{Literature Review and Related Studies:}

\section{1 EFL Intonation Production:}

Scholars have long reported that English intonation relates to several acoustic features and perceptual phenomena such as word-prominence, word-group prominence, intensity, command, reassurance, annoyance, doubt, and concession. It is also defined from different perspectives and with different focuses. Some scholars emphasized the pragmatic meaning and phrasal structure while others highlighted intonation patterns or tones (Liu \& Reed, 2021). For Wells (2006, p. 1), it is the "study of how the pitch of the voice rises and falls and how the speakers use this pitch variation to convey linguistic and pragmatic meaning". Similarly, Trask and Stockwell (2007, p. 125) defined it as "variation in the pitch of the voice during speech which rises and falls in structured ways during each، and the resulting pattern is the intonation pattern of the utterance". According to Ladd (2008, p. 4), it is "the use of suprasegmental phonetic features to convey post-lexical or sentence-level pragmatic meanings in a linguistically structured way". Levis and Wichmann (2015, p. 139) delineated it as "the use of pitch variations in the voice to communicate phrasing and discourse meaning in varied linguistic environments". Pickering $(2018$, p. 3) defined it as "the grammatical system that includes 
our use of pitch, pause, and prominence (or sentence stress)". Intonation patterns are also called intonation contours, pitch patterns or pitch contours (Richards \& Schmidt, 2010).

Traditionally, American linguistics has made a distinction between tone as referring to word-level pitch patterns and intonation as referring to sentence-level or utterance-level pitch patterns (and often incorporating stress patterns as well). That is not made in British linguistics, where tone is a component of intonation, meaning pitch patterns that function above the word level (Pennington \& RogersonRevell, 2019). In this context, Halliday (1967, as cited in Hodgetts, 2020, p. 53) argues that intonation can be seen as a system of three phonological and systematic variables: tonality, tone, and tonicity. "Tonality is used to describe tone units or intonational phrases that are constrained both physically (speakers need to breathe at certain points while speaking) and cognitively (utterances are used to express ideas). These intonation boundaries are marked by a fall in pitch and a reduction in speed, for instance, after the final accented syllable". According to Brazil (1997, as cited in Hodgetts, 2020, p. 53), such boundaries are also marked by a pause. "Tone is used to describe the fall or rise in pitch during utterances, and tonicity is used to describe the placement of the nucleus in an intonational phrase".

As stated by Low (2015), the main function of intonation is simply to get the listener to easily understand the spoken message. Still, there is no exclusive mapping from intonation to meaning. Moreover, intonation is considered to be "culture- and language specific. Thus, it is possible to anticipate that in the context of English as an International Language (EIL), if speakers aim to acquire multicultural competence, they will need to learn and understand the functions of intonation in their listeners' variety/varieties of English" (p. 119). According to the British model of intonation, pitch contours are distinctive in two functional (i.e., grammatical or semantic) terms. "Seen from the grammatical perspective, the contours may be used to demarcate speech. From the semantic perspective, the contours serve the function of signaling a difference in meaning" (p. 115). 
According to Wells (2006) and Roach (2009), there are four main functions of intonation: attitudinal, accentual, grammatical, and discoursal. The attitudinal function helps the speaker to express his/her attitudes and emotions- to show shock or surprise, pleasure or anger, interest or boredom, etc. For instance, the utterance I TOLD you so- with stress and a noticeable pitch rise on the word told, followed by falling pitch over the end of the sentence- expresses annoyance. This is done by tone. The accentual (also called focusing or informational) function is to indicate which syllables are prominent or stressed in an utterance and to draw the listener's attention to these prominent syllables. This is done by tonicity and by the placement of other accents. "Accentuation is combined with the choice of tone to present some longer stretches of the message as constituting the foreground of the picture being displayed, while leaving other stretches as background. These are pragmatic functions" (Wells, 2006, p. 11).

The grammatical function assists the listener to mark the beginning and end of grammatical units such as clauses and sentences (the demarcative function). This is done by tonality. It also helps the listener to distinguish between statements and questions and to disambiguate sentences that otherwise can have two meanings (the syntactic function). For example, the word ready? - said with rising intonation- is a question, while the same word with falling intonation is a statement. This is mainly done by tone. The discoursal function helps the listener to distinguish between new and old information by assigning more prominence to parts of the utterance expressing new information and de-emphasizing those parts containing given or old information. It also helps the speaker to control the conversational floor as it signals whether or not the speaker has come to the end of the point that he/she is making and whether he/she wants to keep talking or is ready to give another speaker a turn (Roach, 2009; Wells, 2006).

Wells (2006) mentions two additional functions of intonation to be considered: the psychological and indexical. Regarding the psychological function, "intonation helps to organize speech into smaller units that are easy to perceive, memorize, and perform. That is why tonality is needed". As for the indexical function, "intonation may act as a marker of personal or social identity. What makes mothers sound like mothers, 
clergymen sound like clergymen, officials sound like officials? Partly, their characteristic intonation" (p. 12).

The basic building block of intonational analysis is the tone unit (also called the tone group). There are both external and internal criteria that allows for the identification of tone unit boundaries. In terms of external criteria, tone unit boundaries may be signaled by the presence of a pause, "anacrusis (the presence of a series of unstressed syllables occurring at the beginning of an utterance and which are produced very quickly and typically contain a lot of week or reduced vowels as they tend to be function words)", final syllable lengthening, and a change in pitch level or direction of unaccented syllables (Low, 2015, p. 116). Concerning the internal criteria, the tone unit comprises several parts. The most important part contains the syllable on which a change of pitch begins: the tonic/nuclear syllable. The ways in which linguists have divided the tone unit into its different parts are not always the same. "The following simplified diagram shows the main parts of a tone unit together with different divisions and terms which have been used, where the first syllable of the word very is the onset, the first prominent syllable in the tone unit, and the first syllable of the word story is the tonic syllable, where the pitch of the speaker's voice begins to fall" (Richards \& Schmidt, 2010, p. 602-603). In this context, intonation is "the property of the tone unit" (Halliday \& Greaves, 2008, p. 41).

\section{Figure 1}

The main parts of a tone unit with its different divisions and terms (Richards \& Schmidt, 2010, p. 602)

\begin{tabular}{|c|c|c|c|c|}
\hline \multirow{4}{*}{$\begin{array}{l}\text { Crystal } \\
\text { Halliday } \\
\text { Brazil }\end{array}$} & $\begin{array}{l}\text { unstressed } \\
\text { syllables }\end{array}$ & $\begin{array}{l}\text { onset } \\
\text { first } \\
\text { stressed } \\
\text { syllable }\end{array}$ & $\begin{array}{l}\text { tonic syllable } \\
\text { where major } \\
\text { pitch } \\
\text { movement } \\
\text { begins }\end{array}$ & $\begin{array}{l}\text { continuation } \\
\text { and } \\
\text { completion } \\
\text { of pitch } \\
\text { movement }\end{array}$ \\
\hline & (prehead) & head & nucleus & (tail) \\
\hline & \multicolumn{2}{|c|}{ pretonic } & \multicolumn{2}{|c|}{ tonic } \\
\hline & $\begin{array}{l}\text { (proclitic } \\
\text { segment) }\end{array}$ & tonic & egment & $\begin{array}{l}\text { (enclitic } \\
\text { segment) }\end{array}$ \\
\hline e.g. & That's a & VERY TALL & STO & $r y$ \\
\hline
\end{tabular}


The tone system consists of five distinct tones realized by movements in pitch: falling, rising, level, fall-rising and rise-falling. "The falling tone is used to indicate completion of a speaking utterance (e.g., I have told him a Vbout it.). The rising tone is used to ask a question (e.g., Mary can / swim?) or to indicate that there is more to come in the utterance, such as the case of an open listing of items or options. The level tone is used commonly as a filled pause or filler for thinking (e.g., I was --- um unsure at first.)". The fall-rising indicates doubtfulness (e.g., That might be how you $\sqrt{ }$ think.) while the rise-falling intonation indicates surprise (e.g., You were ${ }^{\wedge}$ right.) (Low, 2015, p. 118-119).

More precisely, some intonation contours have strong associations with specific sentence types. According to Richards and Schmidt (2010), declarative sentences "have an abrupt pitch rise on the last stressed word of the sentence followed by a fall. For example, the sentence Language is a social phenomenon typically has an intonation contour consisting of a rise on the first syllable of social, followed by a gradual fall over the remaining syllables of the sentence". Yes-no questions (e.g., Is language a social phenomenon?) usually "have a long gradual rise in pitch from the beginning to the end of the sentence" (p. 299). As for wh-questions, they have the same intonation contour as declarative sentences. For instance, "in the question What kind of phenomenon is language?, the abrupt pitch rise is usually on the first syllable of the word language". Questions of choice (e.g., Is language a social, psychological, or biological phenomenon?) typically "exhibit list intonation, with a short pitch rise on each option presented by the speaker (social, psychological) except the last (biological), which has the rise-fall associated with finality". Tag-questions (e.g., Language is a social phenomenon, isn't it?) typically "have declarative intonation on the main clause, followed by rising intonation on the tag if the speaker is requesting confirmation and falling intonation on the tag if the speaker is requesting agreement" (p. 300).

Such features and functions of intonation should therefore be presented and incorporated in EFL courses, and particularly the ones where speaking skills constitute a prominent element (Hodgetts, 2020). Recent literature on using intonation-based instruction in EFL learning revealed that it may be beneficial in promoting students' speech intelligibility (Elesery, 2021), listening comprehension (Alsaddon, 2021; 
Elesery, 2021; Hasanvand, Mehrdad, \& Tabar, 2016), oral reading performance in terms of focus, pause, and reading rate (Çelebi \& Börekçi, 2020), and schematic knowledge for making inferencing (Barati $\&$ Bakhtiarvand, 2016). To the researcher's knowledge, few studies were conducted to develop the EFL intonation production ability of English majors (Abdu-Allah, 2013; Ansari, Mehrdad, \& Ahmadi, 2016; Baresh, Ali, \& Darmi, 2019; Chootharat, Veerachaisantikul, \& Junnak, 2016; Damar, 2014; Eissa, 2019; Mirzaei, Abdollahian, \& Ranjbar, 2012; Namaziandost, Esfahani, \& Hashemifarnia, 2018; Seenak, 2017; Sugiarto, Prihantoro, \& Edy, 2020). In the Egyptian context, dramatized scenarios (Abdu-Allah, 2013) were found to be effective in developing students' EFL intonation production. In the Arab region, the hybrid problem-based learning approach in a Libyan University (Baresh et al., 2019) and the digital storytelling strategy in a Saudi one (Eissa, 2019) were utilized to improve the students' speaking performance in terms of grammar, vocabulary, pronunciation, and intonation.

At a global level, Mirzaei et al. (2012) explored the role that the increased perceptual saliency of FL input features or output flaws, and hereby promoting FL students' noticing (through planned instructional activities) can play in their use of correct English intonation patterns. Damar (2014) reported the positive impacts of using content-based videos in a Listening and Phonetics course which enabled Turkish students to produce and perceive different stress and intonation patterns in words, phrases, and sentences. Ansari et al. (2016) studied the impact of applying music on learning the intonation patterns of Iranian students across different levels of musical intelligence. Chootharat et al. (2016) aimed to improve Thai students' pronunciation focusing on word stress and intonation through the role-playing technique and to increase their ability in speaking English for communication. Seenak (2017) investigated the effects of self- and peer-assessments on Thai students' intonation ability, their lower- and higher-order thinking skills, and their attitudes towards self- and peer-assessments in intonation learning. Recently, Namaziandost et al. (2018) examined the effectiveness of authentic videos in the improvement of Iranian students' prosodic ability. Sugiarto et al. (2020) explored the impact of the shadowing technique on Indonesian students' English pronunciation in terms of phonemes, combinations of sounds, linkage of sounds, stress, and intonation. 


\section{2 Computer-assisted Pronunciation Training (CAPT):}

Within the fields of SL/FL acquisition and applied linguistics, computer-assisted pronunciation training (CAPT) is a relatively recent development. It refers to using specific technological tools to detect and diagnose mispronunciations in students' speech, and then help them to correct such errors in both formal and informal learning contexts (Agarwal \& Chakraborty, 2019). Some of its benefits include the motivational effect created by its novelty, the availability of multimodal resources incorporating print, audio, and video, and the enhanced mobility of being able to study anytime anywhere, facilitating individualized, self-paced learning. It can also provide unlimited opportunities for repetition and imitation as well as exposure to a wide range of target language speech. Its main advantage is the opportunity to provide automated feedback, and the use of speech technologies such as speech analysis, automatic speech recognition (ASR), and speech synthesis can be particularly beneficial for giving such feedback on different aspects of pronunciation (Pennington \& Rogerson-Revell, 2019).

A common criticism of CAPT, is that technology often takes precedence over pedagogy, with the result that many CAPT resources often have a limited curriculum focus (typically, on phonemes), a narrow range of activity types (e.g., minimal pairs discrimination), and generalized feedback (e.g., correct or incorrect)" (Pennington \& Rogerson-Revell, 2019; Rogerson-Revell, 2021). In response to this concern, Pennington (1999, p. 434) offers some principles for the design of CAPT materials: "(a) establishing baseline, reference accents for instruction, (b) setting measurable goals and performance targets, (c) being designed to build skills from easier to more challenging exercises, (d) linking pronunciation to other aspects of communication, and (e) raising students' awareness of how their L1 phonological systems differ from the system of the target language". Similarly, Hardison (2018, pp. 479-480) raises some issues to be considered when incorporating CAPT into the learning and teaching process: (a) assessment of improvement following training, "(b) speech perception-production link (transfer of perception training to production improvement, (c) role of variability in training (e.g., number of stimuli, phonetic contexts), (d) role and 
interpretability of the display in training (Is a native speaker model presented for students to imitate or is it used as a feedback after students have produced their own utterances?), (e) role of the teacher/tutor, and (f) students' perceptions of the effectiveness of the training".

\section{Speech Analysis Technology:}

While it is considered one major component of CAPT, speech analysis has not been widely used in language learning classrooms. Initially, teachers were put off by the high cost of speech analysis programs such as VisiPitch or Speech Viewer. The systems freely available, such as Praat and WaveSurfer, were for some time well-known in the speech research community but relatively known in the language learning community. These systems are based on the principle that "the pitch contour and sound waveform of a student's utterance are displayed alongside those of a model utterance. Together with a teacher, or on his/her own, the student examines the differences in the visualizations of the two utterances, with the goal of achieving a better match in terms of pitch, duration, and intensity" (Hincks, 2015, p. 509).

Though its visual feedback was successfully used to detect segmental features in minimal studies (Kartushina, Hervais-Adelman, Frauenfelder, \& Golestani, 2015; Olson, 2014; Wulandari, Rodliyah, \& Fatimah, 2016), speech analysis technology is usually advocated to improve suprasegmentals (Chun, 2002; Farida \& Said, 2016; Gut, 2013; Hincks, 2015; Levis \& Pickering, 2004; Li, 2019; Pennington \& RogersonRevell, 2019). This is because they cannot be seen in the same way that the articulation of the segmentals is often observable, through manipulating the articulatory apparatus (Bliss, Abel, \& Gick, 2018). However, a non-specialist "can interpret a pitch contour representing intonation more intuitively than a spectrogram, making visual feedback a more natural fit for teaching intonation" (Imber, Maynard, \& Parker, 2017, p. 196). In this context, pitch visualization is employed mainly to training short utterances that rely on pitch movements to distinguish meaning. Longer discourse is harder to display and interpret at a smallgrained level, but can be useful to illustrate, for example, raised pitch with the introduction of a new topic, falling pitch across the length of an utterance, and tone choice (Levis \& Pickering, 2004). The speech waveform, when accurately interpreted, reveals information about 
relative syllable length so that students can observe durational differences between stressed and unstressed syllables (Hincks, 2015).

Automatically comparing two pitch contours for the purpose of giving CAPT feedback is not simple. It needs to be immediate, pertinent, correct, and given in a form that students can benefit from and to suggest ways to address errors (Levis, 2007). To ensure its efficacy in improving EFL intonation, a teacher should be available for guidance and interpretation and be encouraged to work with students individually or in small groups (Imber et al., 2017; Pearson, Pickering, \& Da Silva, 2011). This is because most language learners have little knowledge of acoustics; they need help to understand these displays. The huge amounts of raw acoustical data can be overwhelming and cause difficulty in determining which features need focus and how to modify their speech to approximate a model. Besides, if a student and a model speaker have very different voice ranges, it can be hard to see the relationship between two pitch curves, and they may not be displayed with the proper alignment. For better results, it should be adjusted to respond to the vocal range of an individual speaker (Hincks, 2015). Furthermore, teachers should help their students recognize which features of the acoustic display are relevant to their errors, so that they can learn to interpret a display and pinpoint their main problems, specifically those that impact their intelligibility (Imber et al., 2017).

\section{Praat:}

Praat (www.praat.org) (Dutch for 'speech', now in version 6.1.49) is a computer program developed in 1991 by Paul Boersma and David Weenink at the University of Amsterdam to analyze, synthesize, and manipulate speech visually. It became freely available, downloadable, and usable in late 1995 (version 3.1) (Low, 2015). It is constantly updated and so are its tutorials to suit the needs of both beginners and experts ( $\mathrm{Li}, 2019)$. It offers the possibility to record mono and stereo sounds. It accepts many types of sound files such as AIFC, AIFF, FLAC, NIST, but WAV and MP3 give the clearest picture. If users want to analyze voice models extracted from various sources whose file formats are not included in the program, they must convert the sound files into WAV or MP3 before analysis (Osatananda \& Thinchan, 2021). Besides, its TextGrid-Objects can be created in order to transcribe and annotate 
sound objects. It also allows for creating artificial sounds (e.g., pause, murmur) with certain mathematic formulas (Farida \& Said, 2016). Its standard display (see Figure 2) shows: (a) a waveform, for illustrating intensity and the presence or absence of linking and pausing, (b) a spectrogram, for pinpointing segmentals and word boundaries, (c) a pitch contour, for measuring pitch range and identifying stressed syllables, and (d) and timing bars, for evaluating speaking time and vowel duration (Imber et al., 2017).

Figure 2

Praat display (Imber et al., 2017, p. 198)

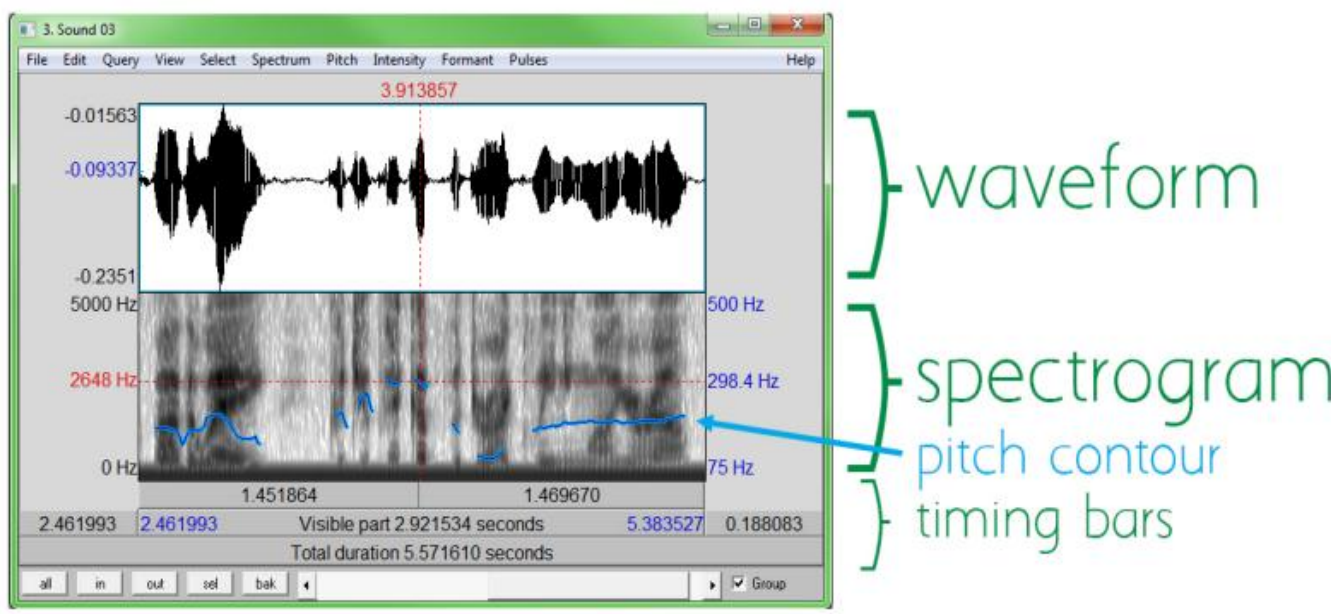

Using Praat, intonation proficiency is usually assessed in terms of prominence and tone choice. Prominence is identified as the syllable that caries the main stress or emphasis in a tone unit. When exploring prominence, pitch, duration, and loudness constitute its three associated features. The acoustic properties of these features are termed fundamental frequency or F0 (measured in hertz or $\mathrm{Hz}$ ), length (measured in milliseconds or seconds), and intensity (measured in decibels or $\mathrm{dB}$ ), respectively. While fundamental frequency involves the acoustic measurement of what is produced physiologically (the number of times that the vocal cords vibrate), pitch, hence, refers to how fundamental frequency is perceived by the listeners, i.e., whether a sound is high or low, and whether a sound is higher or lower than another and by how much. Regarding length, it means the physical duration/timing of articulatory movements of a sound, i.e., whether a sound is long or short, 
and whether a sound is longer or shorter than another and by how much. But acoustically, it refers to the relative duration of sounds and syllables when these are linguistically contrastive. Intensity, which is a physical characteristic related to the amount of energy exerted in producing a sound, is based on the size of the vibrations of the vocal folds, resulting from variations in the pressure of the air coming from the lungs (Chun, 2002; Ghanem \& Kang, 2018; Low, 2015).

Tone choice is identified by whether the speaker uses a fall, rise, level, fall-rising and rise-falling intonation on the last syllable carrying prominence in a tone unit. For example, Figure 3 clearly shows how the word think is set aside by the speaker from the remaining syllables in the utterance this is just what I THINK. Thus, this syllable can be highlighted as a prominent syllable. Since there is a significant rise at the beginning of that syllable and then a drop towards its end, this prominent syllable can be marked with a rise-falling intonation. (Ghanem \& Kang, 2018).

\section{Figure 3}

The prominent syllable and tone choice of a tone unit (Ghanem \& Kang, 2018, p. 126)

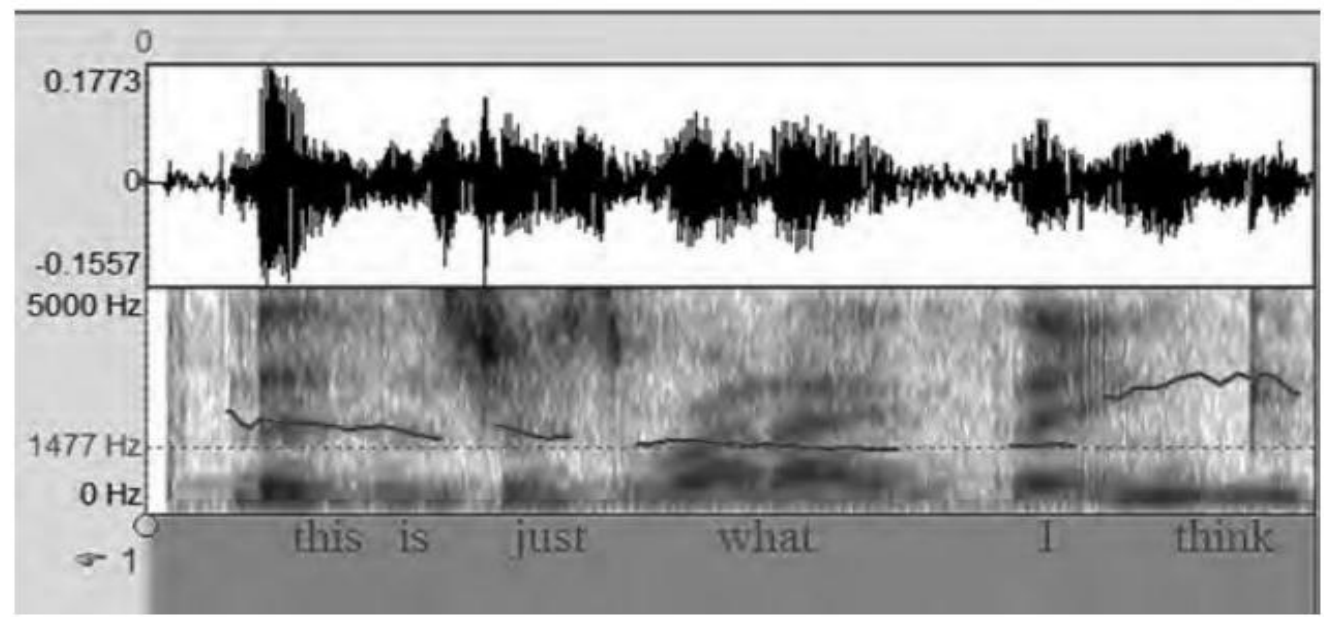

To the researcher's knowledge, there is a paucity of empirical studies devoted to the use of Praat in EFL academic settings. Some of them reported its positive impacts on speech comprehensibility, fluidity, and attractiveness (Jiang \& Chun, 2019), speaking confidence (Arfi, 2016; Jiang \& Chun, 2019), and autonomous learning (Osatananda \& 
Thinchan, 2021). Other scholars found significant gains in students' intonation production due to its application (Bengrait, 2020; Gorjian, Hayati, \& Pourkhoni 2013; Gray, 2015; Hamlaoui \& Bengrait, 2016; Le \& Brook, 2011; Rahmatunisa \& Syarifudin, 2021; Zhuang, 2015). Different procedures of such studies are detailed below.

Le and Brook (2011) investigated whether using Praat could improve the pronunciation skills of EFL students. Participants were 6 lowintermediate students studying at a language center in Hawaii; 5 Koreans and 1 Japanese. They used Praat for phonetic stress pattern analyses and sound manipulation, particularly with yes-no and wh-questions. The results of the pre-post tests showed that Praat enabled students to refine their targeted skills. The results also demonstrated that the training from Praat was transferred to sound production as the students were able to produce these question forms more clearly and naturally in a subsequent dialog reading task. Gorjian et al. (2013) explored the effect of Praat in helping 40 Iranian English majors to acquire the prosodic features of English. Participants were assigned into two groups of experimental (taught using Praat) and control (taught using regular instruction). Both groups were tested before and after experimentation, which lasted for 10 sessions. The results revealed that the experimental group significantly outperformed the control group in producing stress and intonation.

Gray (2015) used a question-and-answer matching task to assess the ability of 26 advanced French-speaking leaners of English to interpret the focus structure of English sentences. The sentences were read out by a native speaker of English in response to a series of wh-questions and presented a mixture of initial, medial, and final focused items. The matching task was performed before and after a 5-week period of training which was part of an obligatory 6-week course on English prosody in the English department at the Université Paris-Est Créteil. Students were trained to use Praat to observe F0 contours of short utterances. They were also shown how the pitch contour tends to be subject to declination as the utterance proceeds. Three nuclear tones were presented and practiced for recognition and production: falling, rising and fall-rising. Overall scores improved significantly, suggesting that the training had a beneficial effect on students' performance. 
Zhuang (2015) examined the effect of using Praat to help EFL university students improve their ability to use English intonation in communication. Participants $(N=32)$ were Brazilian native speakers of Portuguese. They were divided into two groups: an experimental group ( $n=16$ ) which received a 4-week perception training of English intonation with listening practice and Praat photo-reading exercises; there was no production practice during the training, and a control one ( $n$ $=16$ ) which received regular instruction. Students were pre-post tested for the accuracy of intonation production and the acoustic features of intonation. The treatment group significantly improved in the correct use of intonation after the perception training. A significant group difference of the acoustic patterns of intonation after training was also found.

Hamlaoui and Bengrait (2016) investigated the effective use of BetterAccent Tutor and Praat programs for the learning of English intonation among 9 second-year students taking an intermediate-level phonetics course, at the Department of English, University of Guelma, Algeria. They were divided into two groups: an experimental group ( $n=$ 5) which received audio-visual feedback provided by BetterAccent Tutor and Praat to enhance their English intonation renditions and a control one ( $n=4$ ) which listened only to audio-recordings. The experimental method enabled generating, measuring and analyzing intonation contours, pitch and intensity of English wh-questions and tag-questions. The results revealed that the audio-visualization technology support helped the students to identify the errors and to understand the functionality of acoustic features they produce regarding intonation patterns. The results also showed that using BetterAccent Tutor and Praat had a significant impact on wh-questions and tag-questions mean pitch scores.

Bengrait (2020) explored the effect of providing audio-visual feedback to students' production of EFL intonation through using Speech Analyzer and the retrieval of pitch and intensity values with Praat during the third semester of the phonetic course at the Department of English, University of Guelma, Algeria. The study group of second-year students' $(N=10)$ productions were compared to a group of native speakers of American English ( $N=6$, at the Paris Diderot University, France) renditions. The results of both groups were compared in the pre-test 
phase were the participants recorded their productions, and in the posttest phase where students listened, visualized, and compared their pronunciations with native speakers' renditions and re-recorded their performances. The results revealed that the participants succeeded in performing certain English sentences with the appropriate tonal patterns and achieved almost equivalent mean pitch and intensity to that of native speakers.

Rahmatunisa and Syarifudin (2021) analyzed the elements of suprasegmental sound in English debates consisting of stress and intonation by using Praat and students' perceptions toward its use for that purpose. Participants $(N=30)$ were EFL Indonesian students from one class of General English, a compulsory course in Universitas Kuningan. Several instruments were used to collect data including observation, documentation for qualitative data, and questionnaires for quantitative data. Praat was used to analyze the stress and intonation patterns, while questionnaires were used to determine students' perceptions toward the use of Praat in mastering English debate. The results showed that the use of intonation and stress can affect the meaning of speech, especially in debate. Besides, students gave a positive response to the use of Praat in understanding the correct intonation patterns and stress when speaking.

\section{Method and Procedures:}

\section{1 Design and Participants:}

The present study is a control-group pre-post test quasi-experimental study. Participants $(N=40)$ were chosen at random from third-year students in the English Department, Faculty of Education, University of Sadat City, during the first semester of the 2020-2021 academic year. They were divided into two groups: an experimental group $(n=20)$ which was taught using Praat and a control one $(n=20)$ which received regular instruction. The age of those participants ranged from 20 to 21 years old. All students were computer literate.

Before experimentation, participants of both groups were pre-tested using the prepared EFL intonation production test to make sure that both groups are identical in their entry levels of EFL intonation production. Table 1 demonstrates that no statistically significant difference existed between the mean score of the control group and that of the experimental 
group in EFL intonation production on the pre-test $(t=-1.4624, p>$ 0.01 ). This ensures that both groups were fairly equivalent in their entry levels before conducting the experiment.

Table 1

The t-values of the Control and Experimental Groups on the Pre-test

\begin{tabular}{lllllllc}
\hline \multicolumn{1}{c}{ Dimension } & Group & $\boldsymbol{N}$ & $\boldsymbol{M}$ & $\boldsymbol{S D}$ & $\boldsymbol{t}$ & $\boldsymbol{d} \boldsymbol{f}$ & Sig. \\
& & & & & & & \\
\hline 1. & Control & 20 & 11.05 & 0.999 & -0.7597 & 38 & No sig. $>$ \\
Prominence & Exp. & 20 & 11.30 & 1.081 & & & 0.01 \\
2. Tone & Control & 20 & 15.10 & 1.119 & -1.9904 & 38 & No sig. > \\
Choice & Exp. & 20 & 15.80 & 1.105 & & & 0.01 \\
EFL & Control & 20 & 26.15 & 2.033 & -1.4625 & 38 & No sig. > \\
$\begin{array}{l}\text { Intonation } \\
\begin{array}{l}\text { Production } \\
\text { (total) }\end{array}\end{array}$ & Exp. & 20 & 27.10 & 2.075 & & & 0.01 \\
\hline
\end{tabular}

\section{2 The EFL Intonation Production Test (IPT):}

It was used as a pre-post test. It consisted of two questions. The first one included ten sentences with punctuation clues. Students were required to read them aloud, putting stress on the prominent syllables and producing tone patterns correctly. The second question included two main sentences, each one with three different meanings, without punctuation clues, to be read aloud three times with proper intonation according to the italicized explanation given (See Appendix A). Test items were taken from Orion's Pronouncing American English: Sounds, Stress, and Intonation (2011). To establish its content validity, the IPT was submitted to a panel of jurors comprising six Egyptian university professors of applied linguistics/TEFL. They were requested to evaluate the test in terms of clarity of its questions, suitability to the students' academic level and consistency with the objective it aimed to measure. They indicated that the test could be considered a valid measure of EFL intonation production. Its reliability was computed by using the Pearson inter-rater reliability on a group of 14 third-year English majors- out of the study sample- from the Faculty of Education, University of Sadat City, at the beginning of the first semester of the 2020-2021 academic year. The Pearson's correlation coefficient was 0.789 ; thereby reflecting the test reliability. 
To ensure the objectivity of scoring, two raters (the researcher and another EFL lecturer) evaluated the students' EFL intonation production in the pre- and post-tests and calculated the mean. The two raters had the same experience and qualifications. They compared the Praat picture of the students' intonation production with that of the model, to make more accurate judgment than just relying on listening to their audio-recordings. They used a scoring sheet prepared by the researcher to measure students' EFL intonation production. This sheet included two main categories: prominence and tone choice. Prominent syllables were measured by examining F0, length, and intensity. Prominent syllables should show higher pitch frequency, along with darker and longer sound waves. Producing three or two of these features correctly, the student received 1 point. If the student produced only one feature or did not place prominence on the correct syllable, he/she was marked wrong and received zero point. As for tone choice, if the student's utterance demonstrated clear pitch contour of falling or rising, it was marked correct and given 1 point. If the student did not use the right tone, he/she was marked as wrong and received zero for that item. The test items included 24 prominent syllables and 28 tone choices. Thus, the total score of the test was 52 .

\section{3 Experimental Procedures:}

Before experimentation, the researcher pre-tested the participants using the IPT to measure their entry levels in EFL intonation production. Pre-testing took place on 31st October 2020 at the Faculty of Education, University of Sadat City. Students took the test one by one to avoid disturbance where they were required to produce the target sentences. Their voices were audio recorded on Praat and saved for further rating. The experiment was part of the Conversation III course. The first week of the experiment included two 2-hour orientation sessions. The first session aimed at reviewing the conception of intonation, its forms and functions. The second one aimed at training students on using Praat at the Computer and Language Laboratory of the Faculty of Education, University of Sadat City. To facilitate training, video tutorials and guides were used and made available for review purposes. Students were trained on how to (a) download and start up the Praat program, (b) explore its interface and relevant functions in the menu bar, (c) make a speech recording, (d) load and view a speech sample to call up the sound waves 
and spectrogram of it for analysis, (e) get the pitch and intensity values, (f) plot the pitch contours with annotations, and (g) copy and paste the spectrogram from Praat to a Word document.

Moreover, they were instructed in what to look for, how to interpret what they are seeing, and how to reflect on the modifications they might make. They were also trained on how to fill in their Praat-based journals where they were required to take notes in a Word document about their intonation performance (i.e., pitch, length, and intensity) in comparison with that of the model and to paste their initial and enhanced spectrograms with those of the model to make comparisons. Moreover, a WhatsApp group, containing the experimental group students and the researcher, was created to share materials and students' journals and to provide constructive feedback. The researcher also prepared a set of model sentences with their audio recordings. These materials came from Brown and Smith's Active Listening 2 (2007a) and Active Listening 3 (2007b) and Orion's Pronouncing American English: Sounds, Stress, and Intonation (2011).

For weeks 2-4, students were engaged in in-class (6 sessions; two 2hour sessions a week) and out-of-class Praat-based activities to practice using different intonation patterns covering (a) statements and commands, (b) wh-questions, (c) yes-no questions, (d) listing items and giving choices, (e) tag-questions with expectations of yes or no, and (f) speaker's attitude. Prior to each in-class session, students were given 6 short sentences to read and record outside class (initial recordings). The recording of each sentence was less than 10 seconds. That is because if the sound file is longer than 10 seconds, the spectrogram will not be automatically displayed (Low, 2015).

During class time, students were encouraged to visualize, analyze and compare their own recordings to the model's renditions of the intonational compositions, taking notes of any similarities or differences in their journals. Then, they were required to submit their final recordings after multiple trials till reaching a satisfying accuracy level before proceeding to the next item. The teacher moved individually from student to student to help them in the analysis and comparison phase. After that, they continued working in pairs to analyze and compare each 
other's recordings where the researcher circulated, offering help and feedback when needed. At the end of the session, some students shared their recordings and findings to the whole class. Then, they were encouraged to continue practicing outside the classroom on their own. They were given extra 6 sentences to practice recording, visualizing, analyzing, and comparing them to a model while filling in their journals with the target intonation features. Their final productions were submitted after several re-recording attempts. The procedures of the experiment are summarized in Figure 4.

\section{Figure 4}

The experimental procedures of the Praat-based intervention

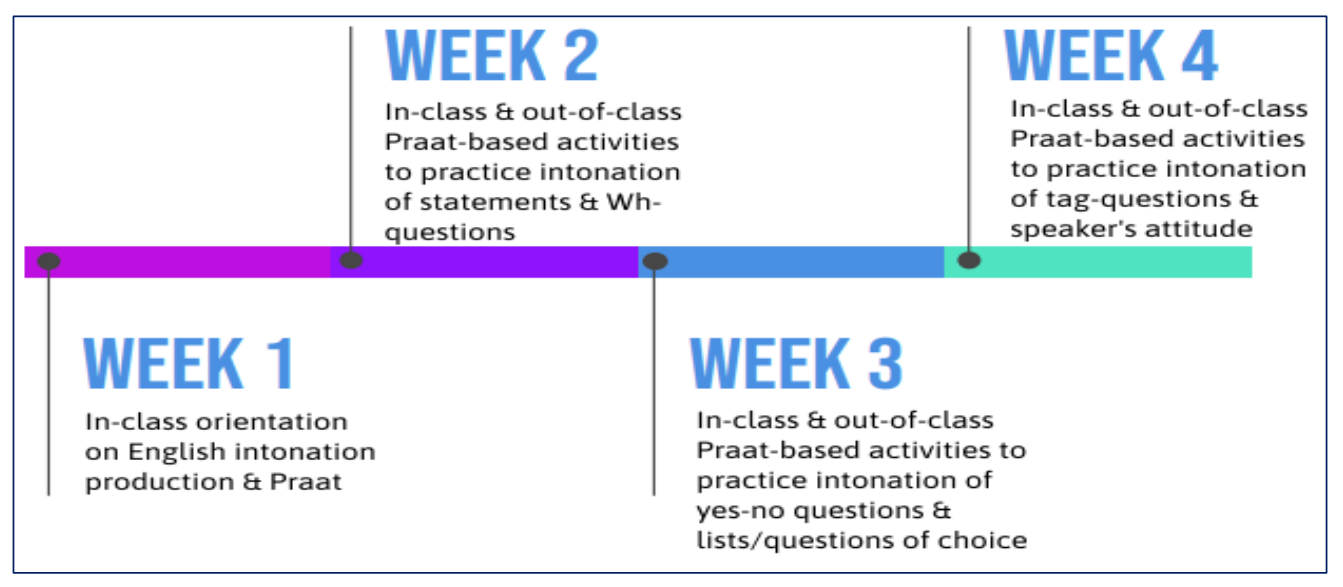

On the WhatsApp group, students shared their recordings, spectrograms, and findings (see Figure 5) and commented on their peers' work. The teacher also provided constructive feedback and posted comments about merits, weaknesses, and areas for future improvement. Accordingly, students edited their productions and posted the enhanced ones again. During experimentation, some students were initially frustrated with technological problems when using Praat. By the end of the experiment, they became more familiar with its display and functions and generated the sound waves, spectrograms and annotations with relative ease. As for the control group students, they received regular instruction with the same set of sentences and audio recordings (6 for inclass use and 6 for home practice) to listen to and imitate. 
Finally, and after a 4-week experiment, the researcher post-tested both groups using the same instrument on 5th December 2020. In order to investigate the hypothesis of the study, the $t$-test for independent samples was administered to compare the mean scores of the control and experimental groups in EFL intonation production on the postadministration of the IPT in order to examine the effect of using Praat.

\section{Figure 5}
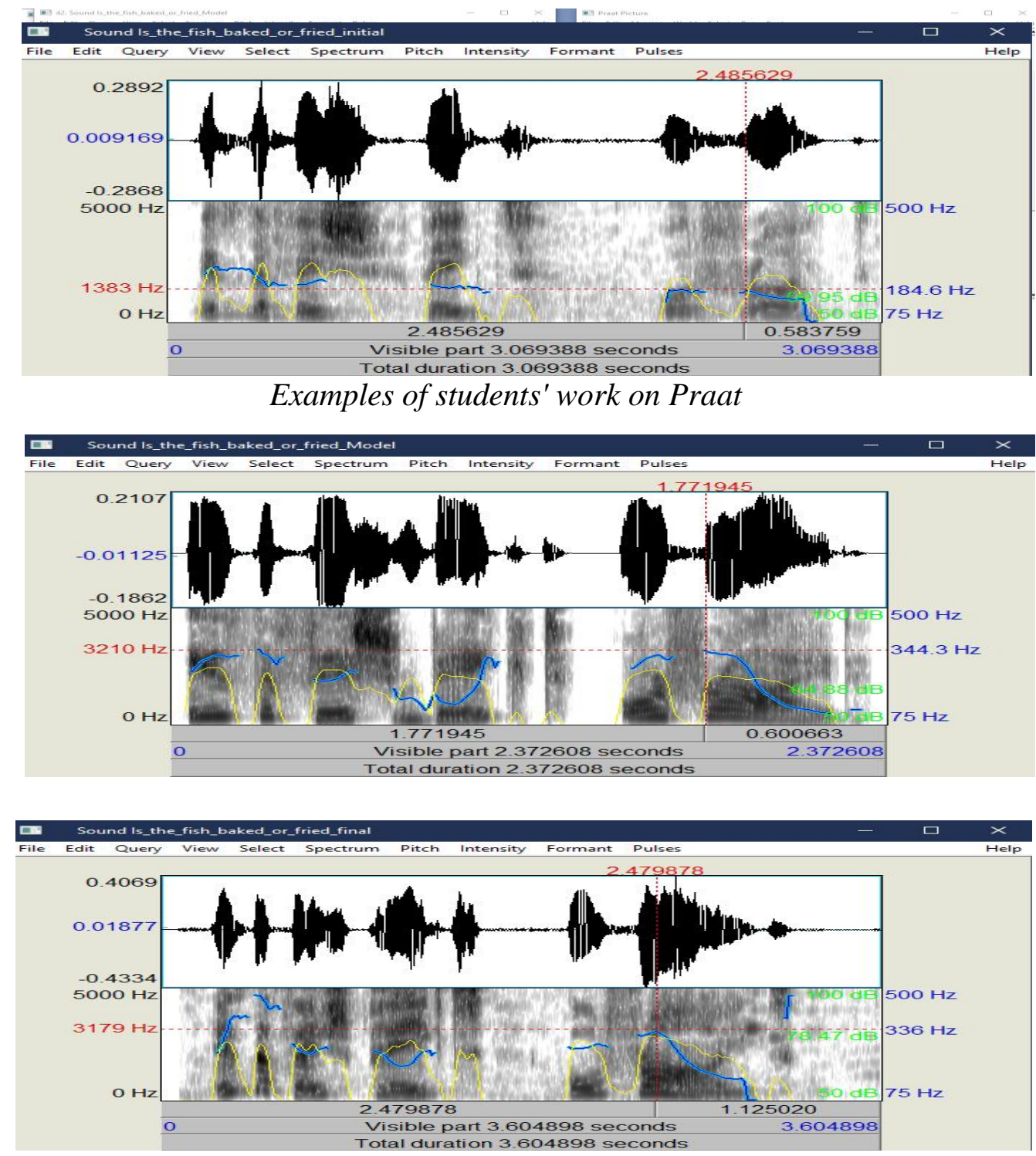

\section{Results and Discussion:}


Table 2 provides the mean scores and the $t$-values of the control and experimental groups in EFL intonation production on the postadministration. The mean scores of the experimental group were higher than those of the control group, thereby indicating the positive effect of using Praat. Table 2 also shows that there were statistically significant differences at the 0.01 level between the mean scores of the control group and those of the experimental group in each skill and in overall EFL intonation production in favor of the latter $(t=-8.2819, p<0.01)$. Thus, the hypothesis of the study was verified, showing that the experimental group achieved significant improvement in EFL intonation production on the post-administration. This improvement could be related to the use of Praat.

Moreover, the effect size was calculated using Cohen's $d$ to measure the magnitude of the mean differences between the control and experimental groups in EFL intonation production on the postadministration. Table 2 shows that the mean scores of both groups in each skill were very different, as indicated by the very large effect sizes. Likewise, the mean scores of both groups in overall EFL intonation production on the post-administration were also very different $(d=$ 2.6190). Using Praat might have contributed to such a positive effect.

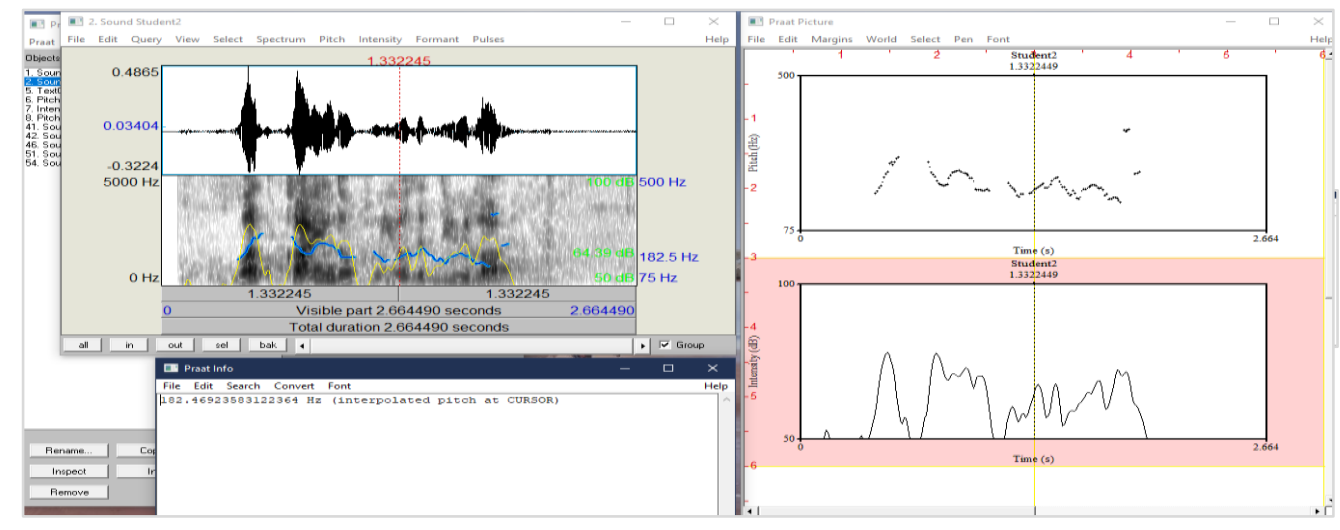


Table 2

The t-values and Effect Sizes of the Control and Experimental Groups on the Post-test

\begin{tabular}{llllllllc}
\hline \multicolumn{1}{c}{ Dimension } & Group & $\boldsymbol{N}$ & $\boldsymbol{M}$ & $\boldsymbol{S D}$ & $\boldsymbol{t}$ & $\boldsymbol{d} \boldsymbol{f}$ & Sig. & Effect Size \\
& & & & & & & & \\
\hline 1. Prominence & Control & 20 & 12.05 & 1.276 & -7.5771 & 38 & 0.01 & 2.3961 \\
& Exp. & 20 & 16.05 & 1.986 & & & & Large \\
2. Tone Choice & Control & 20 & 16.25 & 1.118 & -7.4188 & 38 & 0.01 & 2.3460 \\
& Exp. & 20 & 19.45 & 1.572 & & & & Large \\
EFL & Control & 20 & 28.30 & 2.003 & -8.2819 & 38 & 0.01 & 2.6190 \\
Intonation & Exp. & 20 & 35.50 & 3.332 & & & & Large \\
$\begin{array}{l}\text { Production } \\
\text { (total) }\end{array}$ & & & & & & & & \\
\hline
\end{tabular}

This significant improvement in students' intonation production might be attributable to the different procedures of the Praat-based intervention. Students might have benefited from performing the required in-class and out-of-class Praat-based activities. Using Praat was fundamental in helping students to visualize, analyze and compare their audio recordings with those of a target model till they submitted their final enhanced productions which demonstrated their constructed knowledge and skills. The produced speech signals were graphically presented, and the speech analysis functions of Praat provided students with information about specific features such as pitch, length, and intensity. The visualization of intonation contours of short utterances of speech was also helpful in estimating the level of accuracy associated with the matching or nonmatching of students' pitch patterns to those of a model and in tracking their progress over time. Students' pitch became smoother stressing only the prominent syllables. Their timing and amplitude closely approximated those of the provided model. Their intonation patterns improved using the required tone appropriate for the targeted sentence types and speaker's attitude.

In addition, during the in-class activities, students might have benefited from teacher monitoring and pair work that helped them in interpreting the acoustic display. During out-of-class activities, students had plenty of opportunities for analyzing and comparing the speech input, where they proceeded at a pace with which they were comfortable in processing the immediate automated feedback on their own. Students 
also conducted peer reviewing where they commented on the performance of others on the WhatsApp group. Such peer reflection enabled them to identify the strengths, weaknesses, and areas of improvements of their peer's productions, which in turn increased their motivation to improve them. Teacher constructive feedback and comments might have promoted their intonation production as well. This result agrees with the findings of studies by Le and Brook (2011), Gorjian et al. (2013), Gray (2015), Zhuang (2015), Hamlaoui and Bengrait (2016), Bengrait (2020), and Rahmatunisa and Syarifudin (2021), who concluded that using Praat supports students' EFL intonation skills and provides an effective medium for developing them with the help of its visual feedback features.

\section{Conclusion:}

Based on the results, using Praat enhanced the EFL intonation production of English Majors. Unlike the control group students, those of the experimental group showed significant development in EFL intonation production. During the implementation, students of the experimental group expressed concerns about technical problems and frustration when using Praat. Despite such challenges, by the end of the experiment, students had become more familiar with the display of Praat and gained various benefits from using it, reflected in their EFL intonation production.

\section{Recommendations:}

Based on the results, the following recommendations are offered:

1. Using Praat is recommended for teaching intonation to English majors. Thus, they should be included in the phonetics and conversation curricula as an additional component to supplement the human component.

2. More attention and time should be devoted to EFL intonation as it is very important for those students. That is because they have to master what they are going to use in their future study and career.

3. English majors should be encouraged to use speech analysis programs to develop their EFL intonation production.

4. EFL university lecturers should be acquainted with the new methods and CAPT technologies in teaching EFL intonation. Besides, they should be trained on using them. 


\section{Suggestions for Further Research:}

The following topics are suggested for further research:

1. Replicating the present study with different participants.

2. Investigating the effect of using Praat on students' (a) pronunciation of English consonants, (b) vowel quality, and (c) speaking self-efficacy.

3. Examining the effect of other speech analysis tools on students' intonation production.

4. Exploring the comparative effects of speech analysis and ASR on students' intonational performance. 


\section{References:}

Abd El-Fattah, S. (2018). An edutainment-based program to develop EFL pronunciation skills and engagement among students at Faculty of Education (Unpublished master's thesis). Faculty of Education, Benha University, Egypt.

Abdu-Allah, A. (2013). The effect of dramatized scenarios on the mastery of segmental and suprasegmental features of EFL prospective teachers and their success and failure (Unpublished master's thesis). Faculty of Education, Zagazig University, Egypt.

Agarwal, C. \& Chakraborty, P. (2019). A review of tools and techniques for computer-aided pronunciation training (CAPT) in English. Education and Information Technologies, 24, 3731-3743. https://doi.org/10.1007/s10639-019-09955-7

Albaaly, E. (2017a). EFL teacher challenges in suprasegmental stress. Journal of Faculty of Education-Menoufia University, 2, 1-22.

Albaaly, E. (2017b). Prosody instruction: Intonation challenges of EFL preservice teachers. Journal of Mansura Faculty of Education, 98(1), 1-13.

Alsaddon, R. (2021). Effects of prosody on EFL listening comprehension. Humanities Journal of Imam Mohammad Ibn Saud Islamic University, 59, 285-320. Retrieved from https://0810gwdfn-1105-y-https-searchmandumah-

com.mplbci.ekb.eg/Download?file=YOOQh/7bCkOi3KPi6/M3FlWIH OWKnzrVhXyPGhNLudY=\&id=1130624

Ansari, S., Mehrdad, A., \& Ahmadi, S. (2016). The impact of using music on EFL learners' learning of intonation patterns across musical intelligence levels: The case of Iranian learners. Modern Journal of Language Teaching Methods (MJLTM), 6(1), 86-96. Retrieved from https://mjltm.org/article-1-60-en.pdf

Arfi, A. (2016). Investigating the effects of pronunciation training on EFL learners' speaking confidence: PRAAT oriented model (Master's thesis, Larbi Faculty of Letters and Languages, Ben M'hidi University-Oum El Bouaghi, Algeria). Retrieved from http://bib.univoeb.dz:8080/jspui/bitstream/123456789/3558/1/Investigating\%20the\%2 0Effects\%20of\%20Pronunciation\%20Training\%20on\%20EFL\%20Lear ners $\% 27 \% 20$ Speaking $\% 20$ Confidence $\% 20$ PRAAT $\% 20$ Oriented $\% 20 \mathrm{M}$ odel.pdf

Barati, L. \& Bakhtiarvand, M. (2016). The impact of type of text and intonational clues on Iranian students' schematic knowledge. Modern Journal of Language Teaching Methods (MJLTM), 6(1), 161-169. Retrieved from https://mjltm.org/article-1-60-en.pdf

Baresh, E., Ali, S., \& Darmi, R. (2019). Using hybrid problem-based learning (HPBL) approach to enhance Libyan EFL students' engagement with 
English language. International Journal of Education \& Literacy Studies, 7(2), 9-20. http://dx.doi.org/10.7575/aiac.ijels.v.7n.2p.9

Bengrait, N. (2020). Analysis of Algerian students' English intonation deviations with the employment of Speech Analyzer and Praat programs. Journal of Studies in Language, Culture, and Society 3(1), 2765. Retrieved

from https://www.asjp.cerist.dz/en/downArticle/681/3/1/125430

Bliss, H., Abel, J., \& Gick, B. (2018). Computer-assisted visual articulation feedback in L2 pronunciation instruction: A review. J Second Lang Pronunciation, $4(1)$, 129-153. https://dx.doi.org/10.1075\%2Fjslp.00006.bli

Brown, S. \& Smith, D. (2007a). Active listening 2 ( $2^{\text {nd }}$ ed.). New York, NY: Cambridge University Press.

Brown, S. \& Smith, D. (2007b). Active listening 3 ( $2^{\text {nd }}$ ed.). New York, NY: Cambridge University Press.

Çelebi, S. \& Börekçi, M. (2020). The effect of teaching prosody through visual feedback activities on oral reading skills in L2. The Reading Matrix: An International Online Journal, 20(1), 101-117. Retrieved from https://readingmatrix.com/files/22-2709804j.pdf

Chootharat, S., Veerachaisantikul, A., \& Junnak, C. (2016). Using a role play to improve stress and intonation for Thai learners. Proceedings of the Asian Conference on Arts \& Humanities, 1-13. Retrieved from http://papers.iafor.org/wpcontent/uploads/papers/acah2016/ACAH2016_23142.pdf

Chun, D. (2002). Discourse intonation in L2: From theory and research to practice. Amsterdam: John Benjamins Publishing Company.

Damar, E (2014). Task-based video use for the improvement of English stress and intonation. Journal of Educational and Social Research, 4(2), 227233. http://dx.doi.org/10.5901/jesr.2014.v4n2p227

Eissa, H. (2019). Pedagogic effectiveness of digital storytelling in improving speaking skills of Saudi EFL learners. Arab World English Journal (AWEJ), 10(1), 127-138. https://dx.doi.org/10.2139/ssrn.3367536

Elesery, A. (2021). Shadowing English suprasegmentals for developing EFL learners' listening comprehension and speech intelligibility. Advance. Preprint. https://doi.org/10.31124/advance.13675237.v1

Farida, S. \& Said, P. (2016). Integrating CAPL in teaching English as foreign language: A discourse approach to teach intonation. Al-Athar Journal, 25, 105-113. Retrieved from https://0810gwaom-1105-y-https-searchmandumahcom.mplbci.ekb.eg/Download?file=kOQYGnG7/4ZqHId26sHc897SE Q/CV6KMfAVVU43OGsw $=\& i d=804747$ 
Ghanem, R. \& Kang, O. (2018). Pronunciation features in rating criteria. In O. Kang \& A. Ginther (Eds.), Assessment in second language pronunciation (pp. 115-136). Oxen, Ox: Routledge, Tylor \& Francis Group.

Gorjian, B., Hayati, A., \& Pourkhoni, P. (2013). Using Praat software in teaching prosodic features to EFL learners. Procedia - Social and Behavioral Sciences, 84 34-40. https://doi.org/10.1016/j.sbspro.2013.06.505

Gray, M. (2015). Training L1 French learners to perceive prosodically marked focus in English. In J. Mompean \& J. Fouz-González (Eds.), Investigating English pronunciation: Trends and directions (pp. 174195). Hampshire, UK: Palgrave Macmillan

Gut, U. (2013). Analyzing phonetic and phonological variation on the suprasegmental level. In M. Krug \& J. Schlüter (Eds.), Research methods in language variation and change (pp. 244-259). Cambridge, UK: Cambridge University Press. https://doi.org/10.1017/CBO9780511792519.017

Halliday, M. \& Greaves, W. (2008). Intonation in the grammar of English. London, UK: Equinox Publishing Ltd.

Hamlaoui, N. \& Bengrait, N. (2016). Using BetterAccent Tutor and Praat for learning English intonation. Arab World English Journal (AWEJ) Special Issue on CALL, 3, 99-112. http://dx.doi.org/10.2139/ssrn.2822981

Hardison, D. (2018). Computer-assisted pronunciation training. In O. Kang, R. Thomson, \& J. Murphy (Eds.), The Routledge handbook of contemporary English pronunciation (pp. 478-494). Oxen, OX: Routledge, Taylor \& Francis Group.

Hasanvand, Z., Mehrdad, A., \& Tabar, M. (2016). The effect of teaching prosodic features on pre-intermediate EFL learners' listening comprehension. Modern Journal of Language Teaching Methods (MJLTM), 6(1), 475-484.

Hincks, R. (2015). Technology and learning pronunciation. In M. Reed \& J. Levis (Eds.), The handbook of English pronunciation (pp. 505-519). West Sussex, UK: John Wiley \& Sons, Inc.

Hodgetts, J. (2020). Pronunciation instruction in English for academic purposes: An investigation of attitudes, beliefs and practices. Cham, Switzerland: Springer Nature Switzerland.

Hsieh, J., Dong, D., \& Wang, L. (2013). A preliminary study of applying shadowing technique to English intonation instruction. Taiwan Journal of Linguistics, 11(2), 43-66. Retrieved from http://tjl.nccu.edu.tw/main/uploads/11.2_.2_1_.pdf 
Imber, B., Maynard, C., \& Parker, M. (2017) Using Praat to increase intelligibility through visual feedback. In M. O'Brien \& J. Levis (Eds.), Proceedings of the 8th pronunciation in second language learning and teaching conference, August 2016 (pp. 195-213). Ames, IA: Iowa State University.

Jiang, Y. \& Chun, D. (2019). Web-based intonation training helps improve ESL and EFL Chinese students' oral speech. Computer Assisted Language Learning, 1-29. https://doi.org/10.1080/09588221.2021.1931342

Kartushina, N., Hervais-Adelman, A., Frauenfelder U., \& Golestani, N. (2015). The effect of phonetic production training with visual feedback on the perception and production of foreign speech sounds. Journal of the Acoustical Society of America, 138(2), 817-832. https://doi.org/10.1121/1.4926561

Ladd, D. (2008). Intonational phonology. Cambridge, UK: Cambridge University Press.

Le, H. \& Brook, J. (2011). Using Praat to teach intonation to ESL students. Hawaii Pacific University TESOL Working Paper Series, 9(1, 2), 2-15. Retrieved from https://www.hpu.edu/research-publications/tesolworking-papers/2011/9_1-2_Le\%20Brook.pdf

Levis, J. \& Pickering, L. (2004). Teaching intonation in discourse using speech visualization technology. System, 32(4), 505-524. https://doi.org/10.1016/j.system.2004.09.009

Levis, J. \& Wichmann, A. (2015). English intonation-Form and meaning. In M. Reed \& J. Levis (Eds.), The handbook of English pronunciation (pp. 139-155). West Sussex, UK: John Wiley \& Sons, Inc.

Levis, J. (2007). Computer technology in teaching and researching pronunciation. Annual Review of Applied Linguistics, 27, 184-202. https://doi.org/10.1017/S0267190508070098

Li, K. (2019). The application of Praat in English pronunciation teaching. Advances in Social Science, Education, and Humanities Research, 378, 374-376. https://dx.doi.org/10.2991/assehr.k.191217.150

Liu, D. \& Reed, M. (2021). Exploring the complexity of the L2 intonation system: An acoustic and eye-tracking study. Frontiers in Communication, 6, 1-15. https://doi.org/10.3389/fcomm.2021.627316

Low, E. (2015). Pronunciation for English as an international language: From research to practice. Oxen, Ox: Routledge, Tylor \& Francis Group.

Mirzaei, A., Abdollahian, Z., \& Ranjbar, M. (2012). The role of noticing in L2 learners' production of intonation patterns. The Journal of Teaching Language Skills (JTLS), 4(1), 141-170. Retrieved from https://jtls.shirazu.ac.ir/article_335_5c212051b014e1a98f08ba924688e 406.pdf 
Mohamed, H. (2010). Inter language errors of the third-year student teachers in English pronunciation of suprasegmentals: A diagnostic and remedial study (Unpublished doctoral dissertation). Faculty of Education, Beni-Suef University, Egypt.

Namaziandost, E., Esfahani, F., \& Hashemifarnia, A. (2018). The impact of using authentic videos on prosodic ability among foreign language learners. International Journal of Instruction, 11(4), 375-390. https://doi.org/10.12973/iji.2018.11424a

Olson, D. (2014). Phonetics and technology in the classroom: A practical approach to using speech analysis software in second-language pronunciation instruction. Hispania, 97(1), 47-68. http://dx.doi.org/10.1353/hpn.2014.0030

Orion, G. (2011). Pronouncing American English: Sounds, stress, and intonation ( $3^{\text {rd }}$ ed.). Boston, MA: Heinle ELT.

Osatananda, V. \& Thinchan, W. (2021). Using Praat for English pronunciation self-practice outside the classroom: Strengths, weaknesses, and its application. LEARN Journal: Language Education and Acquisition Research Network, 14(2), 372-396. Retrieved from https://so04.tcithaijo.org/index.php/LEARN/article/view/253273/171964

Pearson, P., Pickering, L., \& Da Silva, R. (2011). The impact of computerassisted pronunciation training on the improvement of Vietnamese learner production of English syllable margins. In. J. Levis \& K. LeVelle (Eds.), Proceedings of the 2 nd pronunciation in second language learning and teaching conference, September 2010 (pp. 169180). Ames, IA: Iowa State University.

Pennington, M. \& Rogerson-Revell, P. (2019). English pronunciation teaching and research: Contemporary perspectives. London, UK: Palgrave Macmillan.

Pennington, M. (1999). Computer-aided pronunciation pedagogy: Promise, limitations, directions. Computer Assisted Language Learning, 12(5), 427-440. https://doi.org/10.1076/call.12.5.427.5693

Pickering, L. (2018). Discourse intonation: A discourse-pragmatic approach to teaching the pronunciation of English. Ann Arbor, MI: University of Michigan Press.

Rahmatunisa, W. \& Syarifudin, S. (2021). The use of Praat in learning English debate in Indonesian EFL classroom. Indonesian EFL Journal, 7(1), 43-50. https://doi.org/10.25134/ieflj.v7i1.3989

Richards, J. \& Schmidt, R. (2010). Longman dictionary of language teaching and applied linguistics ( $4^{\text {th }}$ ed.). Pearson Education Limited.

Roach, P. (2009). English phonetics and phonology: A practical course $\left(^{\text {th }}\right.$ ed.). Cambridge, UK: Cambridge University Press. 
Rogerson-Revell, P. (2021). Computer-assisted pronunciation training: Current issues and future directions. RELC, 52(1), 189-205. https://doi.org/10.1177\%2F0033688220977406

Salem, G. (2020). The effect of using drama activities on developing preparatory stage EFL learners' pronunciation (Unpublished master's thesis). Faculty of Education, Ain Shams University, Egypt.

Seenak, P. (2017). Promoting students' intonation learning through self- and peer-assessments (Doctoral dissertation, Faculty of Liberal Arts, Thammasat University, Thailand) Retrieved from http://ethesisarchive.library.tu.ac.th/thesis/2017/TU_2017_5506320117 _8903_8828.pdf

Sugiarto, R., Prihantoro, P., \& Edy, S. (2020). The impact of shadowing technique on tertiary students' English pronunciation. Linguists: Journal of Linguistics and Language Teaching, 6(1), 114-125. http://dx.doi.org/10.29300/ling.v6i1.3298

Trask, R., \& Stockwell, P. (2007). Language and linguistics: The key concepts ( $2^{\text {nd }}$ ed.). Oxon OX: Routledge, Taylor \& Francis Group.

Tsai, P. (2019). Beyond self-directed computer-assisted pronunciation learning: a qualitative investigation of a collaborative approach. Computer Assisted Language 1-32. https://doi.org/10.1080/09588221.2019.1614069

Wells, J. (2006). English intonation: An introduction. Cambridge, UK: Cambridge University Press.

Wong, C. (2016). Teaching pronunciation to learners of English as a lingua franca. In W. Renandya \& H.Widodo (Eds.), English language teaching today: Linking theory and practice (pp. 241-255). Springer International Publishing Switzerland.

Wulandari, I., Rodliyah, I., \& Fatimah (2016). Using Praat for analyzing segmental features of speech produced by the students of English study program of Uinversitas Brawijaya. ELTICS Journal, 3, 14-25. https://doi.org/10.31316/eltics.v3i1.12

Zhuang, Y. (2015). Evaluating the effectiveness of teaching intonation to learners in an intensive English program (Doctoral dissertation, Northern Arizona University, USA). Retrieved from https://www.academia.edu/34371605/EVALUATING_THE_EFFECTI VENESS_OF_TEACHING_INTONATION_TO_LEARNERS_IN_AN INTENSIVE_ENGLISH_PROGRAM 